\title{
Caffeine Induces Dopamine and Glutamate Release in the Shell of the Nucleus Accumbens
}

\author{
Marcello Solinas, ${ }^{1}$ Sergi Ferré, ${ }^{1}$ Zhi-Bing You, ${ }^{2}$ Marzena Karcz-Kubicha, ${ }^{1}$ Patrizia Popoli, ${ }^{3}$ and \\ Steven R. Goldberg ${ }^{1}$ \\ Sections of ${ }^{1}$ Preclinical Pharmacology and ${ }^{2}$ Behavioral Neuroscience, Behavioral Neuroscience Branch, National Institute \\ on Drug Abuse, National Institutes of Health Intramural Research Program, Baltimore, Maryland 21224, and \\ ${ }^{3}$ Department of Pharmacology, Istituto Superiore di Sanita, 00161 Rome, Italy
}

An increase in the extracellular concentration of dopamine in the nucleus accumbens (NAc) is believed to be one of the main mechanisms involved in the rewarding and motor-activating properties of psychostimulants such as amphetamines and cocaine. Using in vivo microdialysis in freely moving rats, we demonstrate that systemic administration of behaviorally relevant doses of caffeine can preferentially increase extracellular levels of dopamine and glutamate in the shell of the NAc. These effects could be reproduced by the administration of a selective adenosine $\mathrm{A} 1$ receptor antagonist but not by a selective adenosine A2A receptor antagonist. This suggests that caffeine, because of its ability to block adenosine $A 1$ receptors, shares neurochemical properties with other psychostimulants, which could contribute to the widespread consumption of caffeinecontaining beverages.

Key words: caffeine; adenosine; dopamine; glutamate; accumbens; microdialysis
Caffeine is the most consumed psychoactive drug in the world. Although it is a psychostimulant, it is not generally considered a typical drug of dependence (Daly and Fredholm, 1998). Other psychostimulants, such as amphetamines and cocaine, elevate the extracellular concentration of dopamine in the nucleus accumbens (NAc); this is believed to be one of the main mechanisms involved in the rewarding and motor-activating properties of these drugs (Pontieri et al., 1995; Wise and Bozarth, 1987). In addition, augmented extracellular levels of glutamate in the NAc may be involved in the central effects of psychostimulants (Reid et al., 1997). The main mechanism of action of caffeine in the brain seems to be a nonselective competitive blockade of adenosine receptors, in particular adenosine $\mathrm{A} 1$ receptors and A2A receptors (Daly and Fredholm, 1998). In the striatum, adenosine plays an important role as a modulator of both dopamine and glutamate neurotransmission. At a presynaptic level, adenosine, mostly by acting on adenosine A1 receptors localized in nerve terminals, inhibits dopamine and glutamate release (Wood et al., 1989; Okada et al., 1996; Flagmeyer et al., 1997; Golembiowska and Zylewska, 1997). At a postsynaptic level, adenosine decreases dopaminergic neurotransmission by means of specific antagonistic interactions between adenosine and dopamine receptors (Ferré et al., 1997). Thus, caffeine, by antagonizing the effects of endogenous adenosine, can facilitate dopaminergic neurotransmission by stimulating dopamine release and by potentiating the effects of dopamine receptor stimulation (Ferré et al., 1997). Although the latter mechanism is very well established, evidence

Received Feb. 11, 2002; revised May 2, 2002; accepted May 10, 2002.

This work was supported by the Intramural Research Program of the National Institute on Drug Abuse, National Institutes of Health.

Correspondence should be addressed to Dr. Steven R. Goldberg, National Institute on Drug Abuse, National Institutes of Health Intramural Research Program, Behavioral Neuroscience Branch, Preclinical Pharmacology Section, 5500 Nathan Shock Drive, Baltimore, MD 21224. E-mail: sgoldber@intra.nida.nih.gov.

Copyright (C) 2002 Society for Neuroscience $0270-6474 / 02 / 226321-04 \$ 15.00 / 0$ for a dopamine-releasing effect of behaviorally relevant doses of caffeine in brain regions that may mediate its psychostimulant actions has not yet been obtained. Only a previous study by Morgan and Vestal (1989), using in vivo voltammetry, indicated that low doses of caffeine increase dopamine release in the rat caudate putamen. In the present study, by using in vivo microdialysis in freely moving rats, we demonstrate that systemic administration of behaviorally relevant doses of caffeine can preferentially increase the extracellular levels of dopamine and glutamate in the shell of the NAc.

\section{MATERIALS AND METHODS}

Subjects and drugs. Male Sprague Dawley rats, weighing 300-350 gm, were used in all experiments. Animals were maintained in facilities fully accredited by the American Association for the Accreditation of Laboratory Animal Care; all experimentation was conducted in accordance with the guidelines of the Institutional Care and Use Committee of the Intramural Research Program, National Institute on Drug Abuse (NIDA), National Institutes of Health, the directives of the Principles of Laboratory Animal Care (National Institutes of Health publication number 85-23, revised 1985), and the Council of the European Communities (86/809/EEC). Caffeine, the adenosine A1 antagonist 8-cyclopentyltheophylline (CPT), and the adenosine A2A antagonist 5-amino-7-(2phenylethyl)2-(2-furyl)-pyrazolo-[4,3-e]-1,2,4-triazolo[1,5-c]pyrimidine ( $\mathrm{SCH} 58261)$ were administered intraperitoneally in all experiments. Caffeine was dissolved in warm saline, CPT was dissolved in saline with a minimal amount of $1 \mathrm{~N} \mathrm{NaOH}$, and the $\mathrm{A} 2 \mathrm{~A}$ receptor antagonist $\mathrm{SCH}$ 58261 was dissolved in dimethylsulfoxide.

Motor activity experiments. Motor activity was measured in automated activity meters (Automex II; Columbus Instruments, Columbus, $\mathrm{OH}$ ) in habituated animals (30 min), as described in detail previously (Popoli et al., 1998). Total horizontal motor activity (total accumulated counts of a single photocell interruption) was collected for $60 \mathrm{~min}$ after intraperitoneal administration of caffeine $(3,10,30$, and $100 \mathrm{mg} / \mathrm{kg}$ ) or saline. A one-way ANOVA followed by a Dunnett's post hoc test was used for statistical comparisons.

In vivo microdialysis experiments. Concentric microdialysis probes were prepared as described previously (Pontieri et al., 1995). Animals were anesthetized with Equithesin (NIDA Pharmacy, Baltimore, MD), 


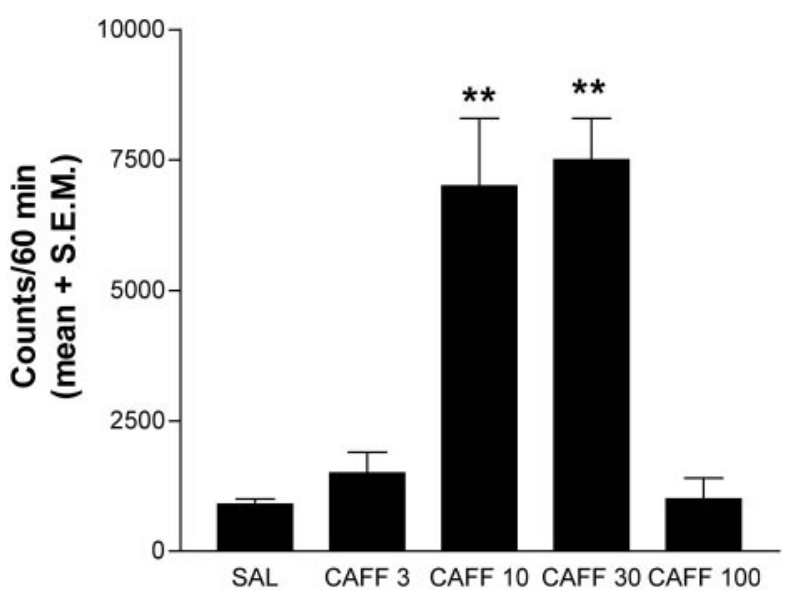

Figure 1. Total horizontal motor activity after intraperitoneal administration of caffeine in habituated rats. The results represent means \pm SEM of the accumulated motor activity counts during the first $60 \mathrm{~min}$ period of observation ( $n=6$ per group). Significant motor activation was obtained with caffeine in a dose of $10 \mathrm{mg} / \mathrm{kg}(C A F F$ 10) and caffeine in a dose of $30 \mathrm{mg} / \mathrm{kg}(C A F F 30) .{ }^{* *} p<0.01$ compared with the group treated with saline $(S A L) . C A F F 3$ and $C A F F 100$ indicate 3 and $100 \mathrm{mg} / \mathrm{kg}$ caffeine, respectively.

and probes were implanted in the left brain hemisphere, either in the shell of the NAc [coordinates with respect to bregma: anterior (A), +2.3; lateral (L), 1.0; ventral (V), 7.8 from the dura] or in the core of the NAc $(\mathrm{A},+1.6 ; \mathrm{L}, 1.8 ; \mathrm{V}, 7.6)$. The experiments were performed on freely moving rats $24 \mathrm{hr}$ after the probe implantation. A solution (in mM) of 147 Ringer's, $4 \mathrm{KCl}$, and $2.2 \mathrm{CaCl}_{2}$ was pumped through the dialysis probe at a constant rate of $0.4 \mu \mathrm{l} / \mathrm{min}$ from immediately after implantation until the beginning of the microdialysis experiment, when it was switched to 1 $\mu \mathrm{l} / \mathrm{min}$ until the end of the experiment. Samples were collected at $20 \mathrm{~min}$ intervals and split into two $10 \mu \mathrm{l}$ fractions. One $10 \mu \mathrm{l}$ fraction was assayed for dopamine content and the other was assayed for glutamate content, using HPLC systems with electrochemical (for dopamine) and fluorescence (for glutamate) detection, as described in detail previously (You et al., 1994; Pontieri et al., 1995). At the end of the experiment, rats were killed with an overdose of Equithesin and methylene blue was perfused through the probe. The brain was removed and placed in a $10 \%$ formaldehyde solution, and coronal sections were cut to verify the probe location. The statistical analysis used was the "summary measures" method (Matthews et al., 1990), using the mean of the three values previous to drug administration and the mean of the six values subsequent to drug administration per animal as the summary measures. Pretreatment and post-treatment dopamine values obtained from the shell and core of the NAc in animals treated with $30 \mathrm{mg} / \mathrm{kg}$ caffeine were analyzed by repeated-measures ANOVA to assess treatment and brain area effects. Pretreatment versus post-treatment values were compared using Student's paired $t$ test to analyze treatment effects; $p$ values shown in the figures refer in all cases to these differences.

\section{RESULTS}

\section{Determination of the motor-activating doses of caffeine}

A dose-response study of the motor activity induced by intraperitoneal administration of caffeine was performed in male Sprague Dawley rats to establish behaviorally relevant doses for microdialysis studies. As reported previously (Daly and Fredholm, 1998), the motor-activation dose-response curve produced by caffeine had an inverted $\mathrm{U}$ shape, with 3 and $100 \mathrm{mg} / \mathrm{kg}$ doses being ineffective and 10 and $30 \mathrm{mg} / \mathrm{kg}$ producing a similar maximal increase in motor activity (Fig. 1).

\section{Caffeine induces a preferential release of dopamine and glutamate in the shell of the NAc}

In subsequent microdialysis experiments, 10 and $30 \mathrm{mg} / \mathrm{kg}$ doses of caffeine induced similar significant increases in extracellular
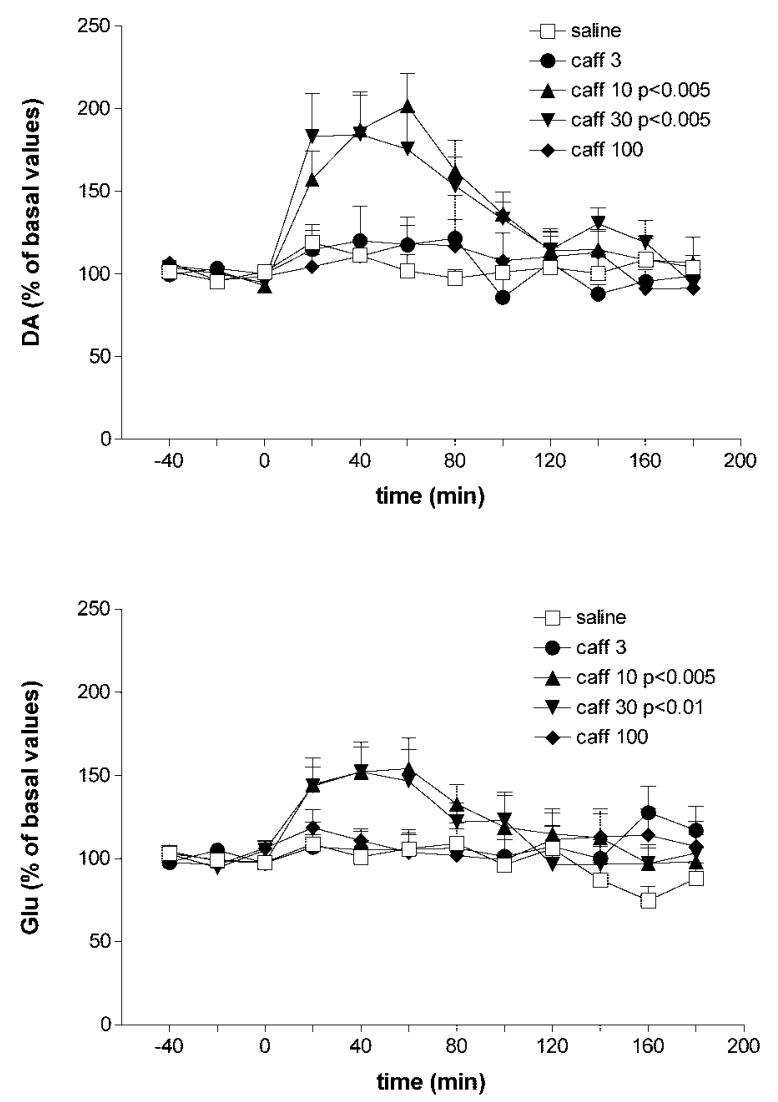

Figure 2. Extracellular concentrations of dopamine $(D A)$ and glutamate $(G l u)$ in the shell of the NAc after intraperitoneal administration of saline or caffeine [3 (caff 3), 10 (caff 10), 30 (caff 30), or 100 (caff 100) $\mathrm{mg} / \mathrm{kg}$ ]. The results represent means \pm SEM of the percentage of basal values of the extracellular concentrations of dopamine and glutamate $(n=6-8$ per group). Basal values were the means of three values before drug administration. Caffeine at doses of 10 and $30 \mathrm{mg} / \mathrm{kg}$ but not at doses of 3 and $100 \mathrm{mg} / \mathrm{kg}$ significantly increased the extracellular levels of dopamine and glutamate (Student's paired $t$ test; only significant results of pretreatment vs post-treatment are shown).

concentrations of dopamine (up by $\sim 100 \%$ ) and glutamate (up by $\sim 50 \%$ ) in the shell of the NAc (Fig. 2). These effects of caffeine were dose- and region-specific. Thus, neither 3 nor $100 \mathrm{mg} / \mathrm{kg}$ of caffeine significantly modified dopamine or glutamate extracellular levels in the shell of the NAc (Fig. 2); in the core of the NAc, $30 \mathrm{mg} / \mathrm{kg}$ caffeine induced a small but significant increase in dopamine levels $(\sim 25 \%)$ and no significant changes in glutamate levels (Fig. 3). This effect was significantly different from that produced by $30 \mathrm{mg} / \mathrm{kg}$ caffeine in the shell of the NAc (interaction between area and treatment factors: $p<0.01$ by repeatedmeasures ANOVA). Basal extracellular levels of dopamine and glutamate were $4.2 \pm 0.3 \mathrm{nM}(n=45)$ and $3.2 \pm 0.2 \mu \mathrm{M}(n=52)$, respectively, in the shell of the NAc and $4.6 \pm 0.6 \mathrm{nM}(n=9)$ and $3.4 \pm 0.6 \mu \mathrm{M}(n=10)$, respectively, in the core of the NAc.

\section{Effects of caffeine on dopamine and glutamate release reproduced by a selective adenosine $\mathrm{A} 1$ receptor antagonist}

Because caffeine is a nonselective adenosine receptor antagonist, the selective adenosine A1 receptor antagonist CPT and the selective adenosine A2A receptor antagonist SCH 58261 were used to investigate the adenosine receptors involved. Low motoractivating doses of both CPT (4.8 mg/kg) and SCH 58261 (2 

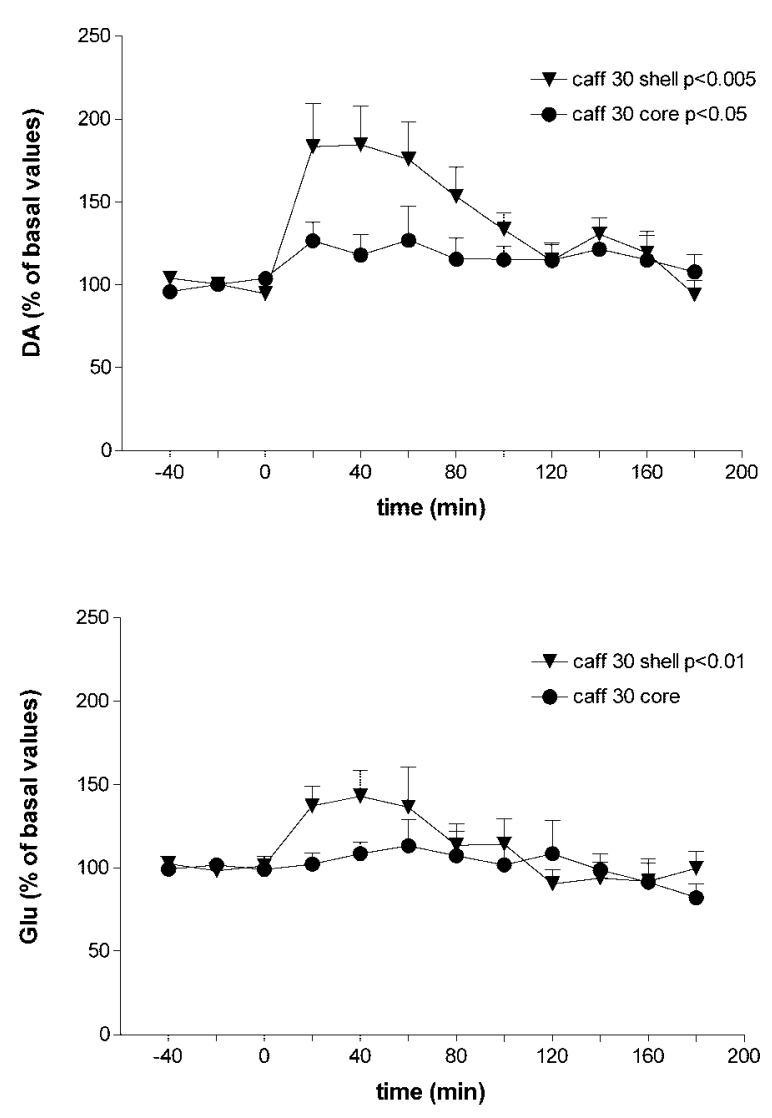

Figure 3. Extracellular concentrations of dopamine $(D A)$ and glutamate $(G l u)$ in the shell and core of the NAc after intraperitoneal administration of caffeine $[30 \mathrm{mg} / \mathrm{kg}$ (caff 30)]. The results represent means \pm SEM of the percentage of basal values of the extracellular concentrations of dopamine and glutamate ( $n=6-8$ per group). Basal values were the means of three values before drug administration. Caffeine $(30 \mathrm{mg} / \mathrm{kg})$ produced a significant increase in the extracellular concentration of dopamine, but not of glutamate, in the core of the NAc (Student's paired $t$ test; only significant results of pretreatment vs post-treatment are shown). This effect was significantly different from that produced by 30 $\mathrm{mg} / \mathrm{kg}$ caffeine in the shell of the NAc (interaction between area and treatment factors: $p<0.01$ by repeated-measures ANOVA).

$\mathrm{mg} / \mathrm{kg}$ ) were used (Popoli et al., 1998). It was found that CPT but not SCH 58261 significantly increased extracellular levels of dopamine and glutamate ( $\sim 100 \%$ in both cases) in the shell of the NAc (Fig. 4).

\section{DISCUSSION}

Dopamine release in either the core or the shell of the NAc has been suggested to be causally related to the locomotor stimulant effects of psychostimulants such as amphetamine (Parkinson et al., 1999; Boye et al., 2001), whereas preferential release of dopamine in the shell of the accumbens has been suggested to be causally related to the rewarding effects of psychostimulants (Di Chiara and Imperato, 1988). The close correlations between the motor-activating effects and the previously described discriminative-stimulus effects of caffeine (Mumford and Holtzman, 1991) and the present microdialysis data are consistent with the possibility that the preferential release of dopamine and glutamate in the shell of the NAc may also be involved in the psychostimulant effects of caffeine. Our hypothesis might seem to be in conflict with the studies by Joyce and Koob (1981), who found that 6-hydroxydopamine lesions in the region of the NAc of
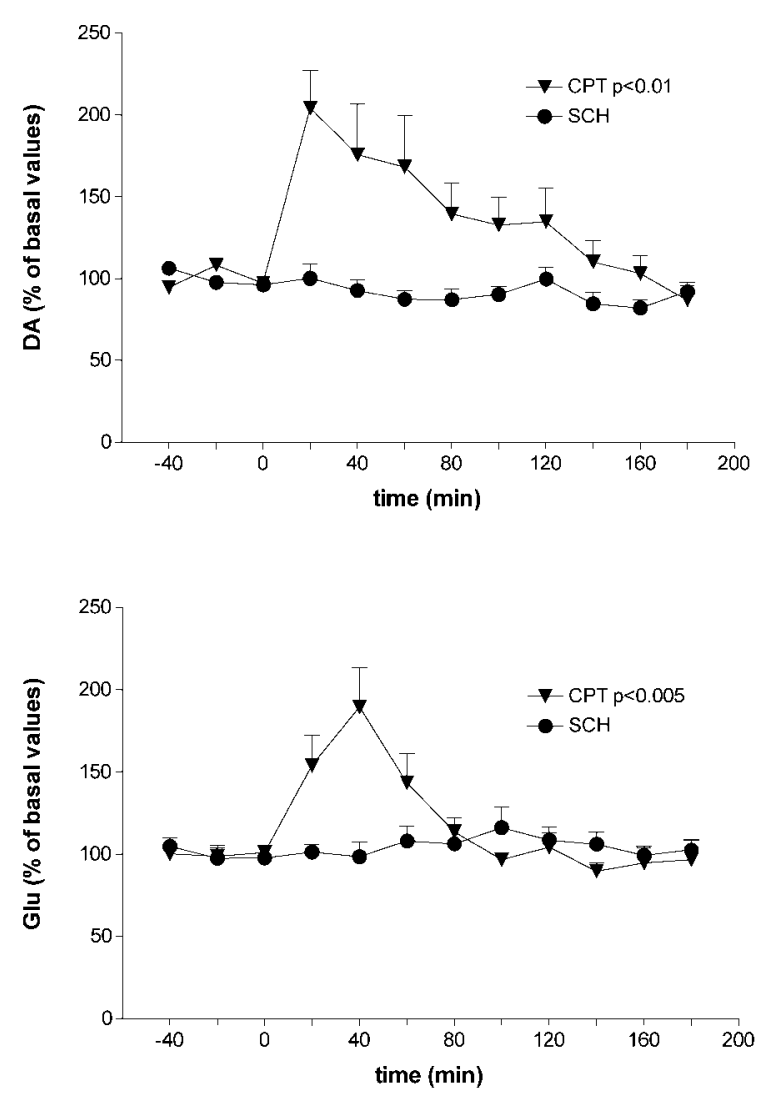

Figure 4. Extracellular concentrations of dopamine $(D A)$ and glutamate $(G l u)$ in the shell of the NAc after intraperitoneal administration of the adenosine A1 receptor antagonist CPT $(4.8 \mathrm{mg} / \mathrm{kg})$ and the $\mathrm{A} 2 \mathrm{~A}$ receptor antagonist SCH $58261(2 \mathrm{mg} / \mathrm{kg})$. The results represent means \pm SEM of the percentage of basal values of the extracellular concentrations of dopamine and glutamate ( $n=6-7$ per group). Basal values were the means of three values before drug administration. CPT but not SCH 58261 produced a significant increase in the extracellular concentrations of dopamine and glutamate (Student's paired $t$ test; only significant results of pretreatment vs post-treatment are shown).

rats blocked the locomotor activation induced by amphetamines but failed to block the locomotor activation induced by caffeine. Based on these results, the authors suggested that caffeine induces locomotor activity by acting independently of presynaptic terminals in the mesolimbic dopaminergic system (Joyce and Koob, 1981; Swerdlow et al., 1986). However, in view of the demonstrated resistance to 6-hydroxydopamine-induced dopamine denervation in the shell versus the core of the NAc (Meredith et al., 1995; Boye et al., 2001), those studies cannot rule out a preferential role of dopamine release in the shell of the NAc on the motor effects induced by caffeine. Nevertheless, it must be pointed out that other striatal regions can also be involved, because a significant although less pronounced effect of caffeine on dopamine release was also observed in the core of the NAc (see the introductory remarks; Morgan and Vestal, 1989). Surprisingly, the highest dose of caffeine $(100 \mathrm{mg} / \mathrm{kg})$ did not produce any effect on extracellular dopamine or glutamate levels in the shell of the NAc. Additional studies are needed to clarify the mechanisms involved in this lack of effect. However, high doses of caffeine are known to exert effects through mechanisms other than adenosine receptor antagonism (e.g., phosphodiesterase inhibition and release of intracellular calcium) (Daly and Fredholm, 1998). 
The results obtained with the selective adenosine A1 and A2A receptor antagonists indicate that the effects of the lower 10 and $30 \mathrm{mg} / \mathrm{kg}$ doses of caffeine on dopamine and glutamate release are related to adenosine A1 receptor antagonism. Thus, although blockade of adenosine $\mathrm{A} 2 \mathrm{~A}$ receptors is currently believed to be the main mechanism responsible for the behavioral-activating (psychostimulant) effects of caffeine (Daly and Fredholm, 1998), as suggested previously (Snyder et al., 1981; Nikodijevic et al., 1991; Kaplan et al., 1992; Popoli et al., 1998), blockade of adenosine A1 receptors also may play a relevant role. At the dose used in the present study, the A2A receptor antagonist had been shown previously to induce pronounced motor activation (Popoli et al., 1998). This rules out the possibility that the motor response is responsible for the dopamine release in the NAc induced by caffeine or the A1 receptor antagonist. The most probable localization of the adenosine A1 receptors that modulate caffeineinduced elevations in extracellular dopamine and glutamate levels is in the terminals of dopaminergic and glutamatergic afferents to the NAc. In fact, there is morphological and functional evidence for this presynaptic localization of adenosine A1 receptors (Wood et al., 1989; Okada et al., 1996; Flagmeyer et al., 1997; Golembiowska and Zylewska, 1997). Also, microdialysis studies have shown previously that the striatal perfusion of A1 receptor agonists and antagonists significantly modifies (decreases and increases, respectively) the striatal extracellular concentrations of dopamine and glutamate (Okada et al., 1996; Golembiowska and Zylewska, 1997). Finally, the increase in the extracellular levels of dopamine induced by caffeine and the A1 receptor antagonist could be related to their effects on extracellular glutamate, in view of the evidence for a facilitatory role of glutamate on striatal dopamine release (Morari et al., 1998).

The region-dependent effects of caffeine in the NAc are similar to those produced by other psychostimulants and addictive drugs, such as amphetamine, cocaine, morphine, heroin, nicotine or $\Delta$ 9-tetrahydrocannabinol ( $\Delta$ 9-THC), all of which preferentially increase extracellular levels of dopamine in the shell of the NAc (Pontieri et al., 1995). Although the degree of increase in extracellular dopamine levels induced by caffeine is lower than that induced by amphetamine and cocaine, it is in the same range as increases induced by the systemic administration of nicotine (Di Chiara and Imperato, 1988), $\Delta 9-\mathrm{THC}$ (Chen et al., 1991), morphine (Di Chiara and Imperato, 1988; Pontieri et al., 1995), or ethanol (Di Chiara and Imperato, 1988). Because these neurochemical changes are often considered central to the development of drug dependence, they could contribute to the widespread consumption of caffeine-containing beverages.

\section{REFERENCES}

Boye SM, Grant RJ, Clarke PB (2001) Disruption of dopaminergic neurotransmission in nucleus accumbens core inhibits the locomotor stimulant effects of nicotine and D-amphetamine in rats. Neuropharmacology 40:792-805.

Chen J, Paredes W, Lowinson JH, Gardner EL (1991) Strain-specific facilitation of dopamine efflux by $\delta 9$-tetrahydrocannabinol in the nucleus accumbens of rat: an in vivo microdialysis study. Neurosci Lett 129:136-140.
Daly JW, Fredholm BB (1998) An atypical drug of dependence. Drug Alcohol Depend 51:199-206.

Di Chiara G, Imperato A (1988) Drugs abused by humans preferentially increase synaptic dopamine concentrations in the mesolimbic system of freely moving rats. Proc Natl Acad Sci USA 85:5274-5278.

Ferré S, Fredholm BB, Morelli M, Popoli P, Fuxe K (1997) Adenosinedopamine receptor-receptor interactions as an integrative mechanism in the basal ganglia. Trends Neurosci 20:482-487.

Flagmeyer I, Haas HL, Stevens DR (1997) Adenosine A1 receptormediated depression of corticostriatal and thalamostriatal glutamatergic synaptic potentials in vitro. Brain Res 778:178-185.

Golembiowska K, Zylewska A (1997) Adenosine receptors: the role in modulation of dopamine and glutamate release in the rat striatum. Pol J Pharmacol 49:317-322.

Joyce EM, Koob GF (1981) Amphetamine-, scopolamine-, and caffeineinduced locomotor activity following 6-hydroxydopamine lesions of the mesolimbic dopamine system. Psychopharmacology 73:311-313.

Kaplan GB, Greenblatt DJ, Kent MA, Cotreau MM, Arcelin G, Shader RI (1992) Caffeine-induced behavioral stimulation is dose-dependent and associated with A1 adenosine receptor occupancy. Neuropsychopharmacology 6:145-153.

Matthews JN, Altman DG, Campbell MJ, Royston P (1990) Analysis of serial measurements in medical research. BMJ 300:230-235.

Meredith GE, Ypma P, Zahm DS (1995) Effects of dopamine depletion on the morphology of medium spiny neurons in the shell and core of the rat nucleus accumbens. J Neurosci 15:3808-3820.

Morari M, Marti M, Sbrenna S, Fuxe K, Bianchi C, Beani L (1998) Reciprocal dopamine-glutamate modulation of release in the basal ganglia. Neurochem Int 33:383-397.

Morgan ME, Vestal RE (1989) Methylxanthine effects on caudate dopamine release as measured by in vivo electrochemistry. Life Sci 45:2025-2039.

Mumford GK, Holtzman SG (1991) Qualitative differences in the discriminative stimulus effects of low and high doses of caffeine in rats. J Pharmacol Exp Ther 258:857-865.

Nikodijevic O, Sarges R, Daly JW, Jacobson KA (1991) Behavioral effects of A1- and A2-selective adenosine agonists and antagonists: evidence for synergism and antagonism. J Pharmacol Exp Ther 259:286-294.

Okada M, Mizuno K, Kaneko S (1996) Adenosine A1 and A2 receptors modulate extracellular dopamine levels in rat striatum. Neurosci Lett 212:53-56.

Parkinson JA, Olmstead MC, Burns LH, Robbins TW, Everitt BJ (1999) Dissociation in effects of lesions of the nucleus accumbens core and shell on appetitive pavlovian approach behavior and the potentiation of conditioned reinforcement and locomotor activity by D-amphetamine. J Neurosci 19:2401-2411.

Pontieri FE, Tanda G, Di Chiara G (1995) Intravenous cocaine, morphine, and amphetamine preferentially increase extracellular dopamine in the "shell" as compared with the "core" of the rat nucleus accumbens. Proc Natl Acad Sci USA 92:12304-12308.

Popoli P, Reggio R, Pezzola A, Fuxe K, Ferré S (1998) Adenosine A1 and A2A receptor antagonists stimulate motor activity: evidence for an increased effectiveness in aged rats. Neurosci Lett 251:201-204.

Reid MS, Hsu K, Berger SP (1997) Cocaine and amphetamine preferentially stimulate glutamate release in the limbic system: studies on the involvement of dopamine. Synapse 27:95-105.

Snyder SH, Katims JJ, Annau Z, Bruns RF, Daly JW (1981) Adenosine receptors and behavioural actions of methylxanthines. Proc Natl Acad Sci USA 78:3260-3264.

Swerdlow NR, Vaccarino FJ, Amalric M, Koob GF (1986) The neural substrates for the motor-activating properties of psychostimulants: a review of recent findings. Pharmacol Biochem Behav 25:233-248.

Wise RA, Bozarth MA (1987) A psychomotor stimulant theory of addiction. Psychol Rev 94:469-492.

Wood PL, Kim HS, Boyar WC, Hutchison A (1989) Inhibition of nigrostriatal release of dopamine in the rat by adenosine receptor agonists: A1 receptor mediation. Neuropharmacology 28:21-25.

You ZB, Herrera-Marschitz M, Brodin E, Meana JJ, Morino P, Hokfelt T, Silveira R, Goiny M, Ungerstedt U (1994) On the origin of striatal cholecystokinin release: studies with in vivo microdialysis. J Neurochem 62:76-85. 